\title{
Case Report: Role of 3D HD Live in Diagnosis of Iniencephaly
}

\author{
Mahmoud Alalfy ${ }^{1 *}$, Alaa Elebrashy ${ }^{2}$, Omaima Idris ${ }^{2}$, Osama Azmy ${ }^{3}$, Sheref $\mathrm{Negm}^{2}$, Ahmed \\ Zakaria $^{2}$, Ahmed Elgazzar ${ }^{2}$, Hasan Gaafar ${ }^{4}$, Ebrahem Magdy ${ }^{5}$, Ahmed el lithy ${ }^{4}$, Rana \\ Abdellah $^{4}$, Alaa Hamed ${ }^{6}$, Mohamed Elhodeby ${ }^{7}$, Samah Aboelsoud ${ }^{5}$, Mohamed Magdy ${ }^{5}$, Elaf \\ Gomaah $^{5}$, Adel Hosny ${ }^{5}$, Ihab Younes ${ }^{8}$, Mohamed Ezz Eldin ${ }^{9}$ \\ ${ }^{1}$ Lecturer of obstetrics and Gynecology, National Research Centre, Head of the Fetal medicine Unit, National \\ Research Centre, Egypt, Consultant at Aljazeerah hospital, Egypt \\ ${ }^{2}$ Professor of Obstetrics and Gynecology, Cairo University, Egypt \\ ${ }^{3}$ Professor of Obstetrics and Gynecology, National Research Centre, Egypt \\ ${ }^{4}$ Assistant professor of Obstetrics and Gynecology, Cairo University, Egypt \\ ${ }^{5}$ Fellow at Cairo fetal medicine unit, Egypt \\ ${ }^{6}$ Lecture of Obstetrics and Gynecology, Alazhar University, Egypt \\ ${ }^{7}$ Lecturer of obstetrics and Gynecology, Misr University, Egypt \\ ${ }^{8}$ Assistant lecturer of obstetrics and Gynecology, Misr University, Egypt \\ ${ }^{9}$ Specialist of Obstetrics and Gynecology, Aljazeerah Hospital, Egypt
}

\begin{abstract}
*Corresponding Author: Mahmoud Alalfy, Lecturer, Obstetrics and Gynecology, National Research centre, Head of the fetal medicine unit, National Research Centre, Consultant at Aljazeerah hospital, Egypt,Email: Mahmoudalalfy@ymail.com
\end{abstract}

Received: October 4, 2018

Accepted: October 15, 2018

Published: October 17, 2018

Abstract

Iniencephaly is characterized by severe retro flexion of the head with the absence of neck due to spinal vertebrae deformities.

Associated Anomalies: Anencephaly, encephalocele, cyclopedia, lack of lower jaw bone, cleft palate, arthrogryposis, clubfeet, holoprosencephaly, spina bifida, lung hypoplasia, omphalocele, gastroschisis, cardiovascular disorders, Congenital diaphragmatic hernias, gastrointestinal atresia, single umbilical artery and renal abnormalities.

Conclusion: Iniencephaly is a lethal congenital neural tube malformation. It is characterized by occipital bone defect, fixed retroflexion of the fetal head and severe lordosis of the cervicothoracic spine.

Differential Diagnosis: Include anencephaly with cervical spinal retro flexion and Klippel-Fiel syndrome.

Keywords: neural tube defect, iniencephaly, spina pifida, anencephaly

\section{DEFINITION}

Iniencephaly is characterized by severe retro flexion of the head with the absence of neck due to spinal vertebrae deformities, it is considered as uncommon anomaly.

Prevalence: 0.1-10:10,000, M: F.

Etiology: Unknown, but genetic, environmental factors are implicated.

Pathogenesis: Unknown.

Recurrence risk: $1-4 \%$.

\section{INTRODUCTION}

Iniencephaly is a rare and lethal congenital malformation of the neural tube characterized by occipital bone defect, cervical dysraphism, fixed retroflexion of the fetal head and severe lordosis of the cervicothoracic spine [2].

There are two types of iniencephaly [3]. Iniencephaly apertus, shows encephalocele and is considered the most severe type. The other group is not associated with the encephalocele (iniencephaly clauses). 
Iniencephaly may be accompanied with anencephaly, encephalocele (cranial brain tissue extrudes from the skull), cyclopedia (fusion of the two eye cavities into one), lack of lower jaw bone, cleft palate, arthrogryposis, clubfeet, holoprosencephaly, spina bifida, low set ears, pulmonary hypoplasia, omphalocele, gastroschisis, cardiovascular disorders, diaphragmatic hernias, gastrointestinal atresia, single umbilical artery and renal abnormalities [1].

\section{CASE REPORT}

26 years old female pregnant 14 weeks came to National Research Centre fetal medicine unit for routine anomaly scan, the ultrasound finding revealed a single living fetus 14 weeks by CRL and shows absent fetal neck with severe retroflexion of the head with upwardly turned face and chin is continous with the chest, Irregular fusion of malformed vertebrae and incomplete closure of vertebral arches and bodies and Upward turned face with chin continuous with chest because of the absence of neck (as demonstrated in images 1 and 2), also US examination revealed restricted upper and lower limbs movements (as shown in Image 3).

A second US scan was made one week later at Cairo fetal ,medicine unit And confirmed the previous findings, then parents were counseled about the poor prognosis and they decided to terminate pregnancy, Induction of abortion was made after approval of religious committee at 15 weeks of gestation and baby was delivered by vaginal delivery at Aljazeerah hospital .

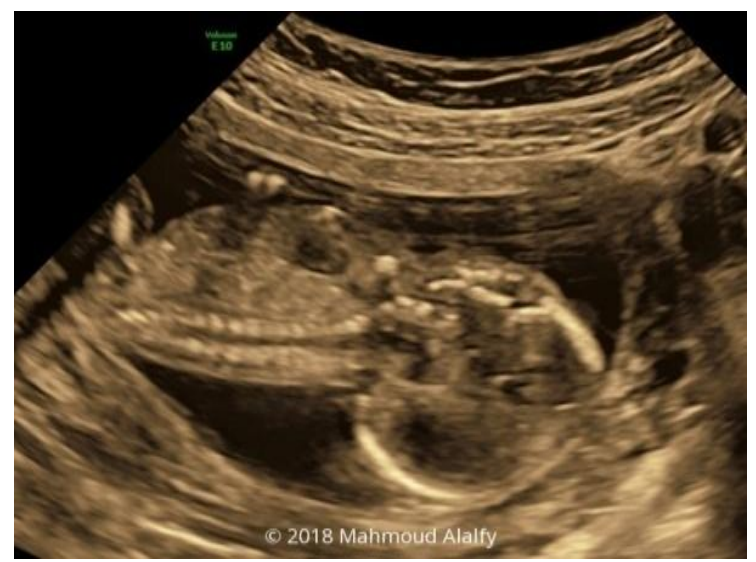

Image1. It shows a sagittal plane in the fetus at 14 weeks and shows severe retroflexion of the head and absent neck

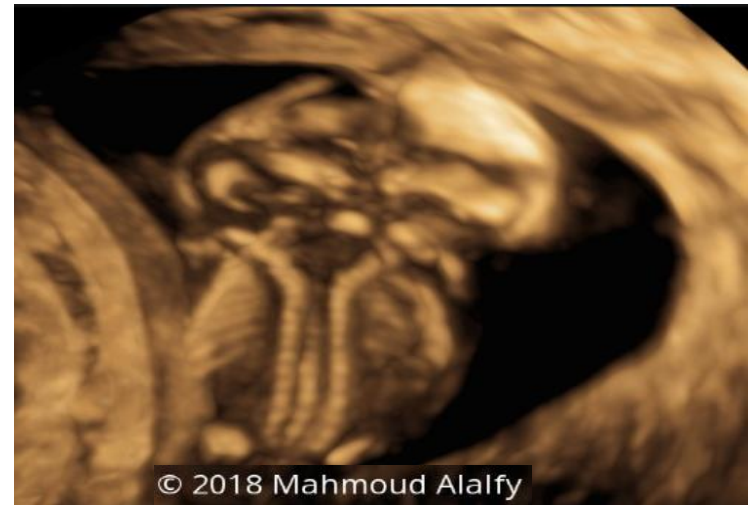

Image2. $3 D$ rendering image demonstrating absent fetal neck with severe retroflexion of the head and widely separated vertebrae

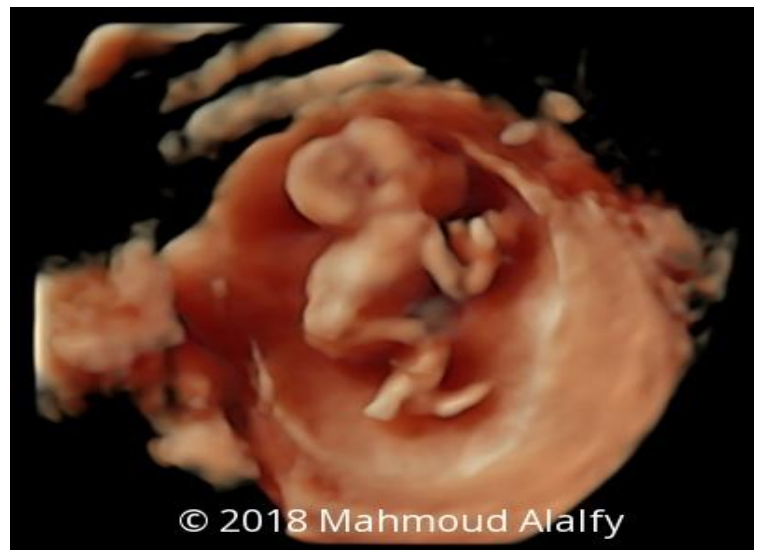

Image3. Shows $3 \mathrm{D}$ images of the fetus at 14 weeks demonstrating head retroflexion and absent neck and restricted fetal limbs movements denoting iniencephaly and Upwardly turned face with chin continuous with chest because of the absence of neck

\section{DISCUSSION}

The term of Iniencephaly is taken from the Greek word inion which means back of the neck and encephalos refer to brain. The fusion of the posterior most part of occipital bone with the back leading to the absence of the neck and retroflexion of head [4].

The diagnosis of iniencephaly antenatally by ultrasonography/Magnetic Resonance Imaging (MRI) or Computed Tomography (CT). The fetus will show typical star gazing appearance on USG and detailed CNS and spine abnormalities may be known by Magnetic Resonance Imaging (MRI) or Computed Tomography (CT) [5].

The keys for diagnosis a case of iniencephaly by ultrasound includes:

1. Irregular fusion of malformed vertebrae. 
2. Incomplete closure of vertebral arches and bodies.

\section{Retroflexion of the cervical spine.}

Upward turned face with chin continuous with chest because of the absence of neck [6]. Our case had all these features and the diagnosis was iniencephaly.

3D US provide a clear additional data about the cervical region of the spine and shows the abnormality in closure of the vertebrae, so it has an important role I diagnosis of iniencephaly.

\subsection{Differential Diagnosis}

Iniencephaly apertus should be differentiated from anencephaly with retroflexion of spine. Also, iniencephaly clausus should be differentiated from Klippel-Fiel syndrome (KFS) and cervical meningomyelocele [9]. Anencephaly shows a total or partial absence of neurocranium and retroflexed head is not covered with skin. However, in iniencephaly the retroflexed head is completely covered with skin. Cervical vertebrae are abnormal in iniencephaly and they are almost normal in anencephaly. In the present case the retroflexed head was completely covered with skin and there was encephalocele. Klippel-Fiel syndrome is characterized by the congenital fusion of any 2 of the 7 cervical vertebrae.

\subsection{Prognosis}

Iniencephaly apertus is always fatal in the neonatal period [7] and our case was diagnosed as iniencephaly apertus and the termination of pregnancy was suggested and the procedure was explained to her. Four cases with a mild iniencephalus clausus have been reported with long-term survival, although in these cases, the deformity was minimal and they should probably have been classified as Klippel-Feil syndrome [8].

\section{REFERENCES}

[1] Baker PN. Prenatal diagnosis. In: Obstetrics by 10 teachers. Book. Power. Publishers. Hodder Arnold. London. 18, 107-108 (2006).

[2] Balci S, Aypar E, Altinok G et al. Prenatal diagnosis in three cases of iniencephaly with unusual postmortem findings. Prenat. Diagn. 21, 558-562 (2001).

[3] Moore CA. Neural tube defects from origin to treatment. Cerebrospinal. Fluid. Res. 3, 6 (2006).

[4] Pungavkar SA, Sainani NI, Karnik AS et al. Antenatal diagnosis of iniencephaly: Sonographic and MR correlation: A case report. Korean. J. Radiol. 8, 351-355 (2004).

[5] Gadodia A, Gupta P, Sharma R et al. Antenatal sonography and MRI of iniencephaly apertus and clausus. Fetal. Diagn. Ther. 27, 178-180 (2010).

[6] Chen CP. Prenatal diagnosis of iniencephaly. Taiwan. J. Obstet. Gynecol. 46, 199-207 (2007).

[7] Nishimura H, Okamoto N. Iniencephaly Handbook of Clinical Neurology. New. York. North Holland. Biochemical. Press. 30, 257268 (1977).

[8] Katz VL, Aylsworth AS, Albright SG: Iniencephaly is not uniformly fatal. Prenat. Diagn. 9, 595-599 (1989).

Citation: Mahmoud Alalfy, Alaa Elebrashy, Omaima Idris, Osama Azmy, Sheref Negm, Ahmed Zakaria, Ahmed Elgazzar, Hasan Gaafar, Ebrahem Magdy, Ahmed el lithy, Rana Abdellah, Alaa Hamed, Mohamed Elhodeby, Samah Aboelsoud, Mohamed Magdy, Elaf Gomaah, Adel Hosny, Ihab Younes, Mohamed Ezz Eldin, Case Report: Role of 3D HD Live in Diagnosis of Iniencephaly. ARC Journal of Gynecology and Obstetrics 2018; 3(3):7--9. DOI:dx.doi.org/10.20431/2456-0561.0303002.

Copyright: (C) 2018 Authors. This is an open-access article distributed under the terms of the Creative Commons Attribution License, which permits unrestricted use, distribution, and reproduction in any medium, provided the original author and source are credited. 